\title{
A comparative study on changes in hemostasis in orthotopic and auxiliary liver transplantation in pigs
}

\author{
Robert J. Porte ${ }^{1}$, Jan D. Blankensteijn ${ }^{2}$, Eduard A.R.Knot ${ }^{1}$, Moniek P.M. de Maat ${ }^{1}$, Theo H.N.Groenland ${ }^{3}$, \\ and Onno T. Terpstra ${ }^{2}$ \\ ' Department of Surgery, St. Joseph Hospital, NL-5500 MB Veldhoven, The Netherlands, \\ ${ }^{2}$ Department of Surgery and ${ }^{3}$ Department of Anesthesiology, University Hospital Dijkzigt, Erasmus University, Dr. Molewaterplein 40, \\ NL-3015 GD Rotterdam, The Netherlands
}

Received January 15, 1990/Received after revision August 16, 1990/Accepted August 30, 1990

\begin{abstract}
We compared blood loss and hemostasis in pigs which had undergone either orthotopic liver transplantation (OLT) (group A, $n=12$ ) or auxiliary heterotopic partial liver transplantation (APLT) (group B, $n=11$ ). Blood samples were taken at regular intervals during and after the operations. In both groups, nine animals survived longer than $24 \mathrm{~h}$ and data from these animals were used for analysis. Median (range) intraoperative blood loss was $825 \mathrm{ml}(250-1500 \mathrm{ml})$ in OLT and $425 \mathrm{ml}(300-750)$ in APLT $(P<0.01)$. Routine clotting times, as the activated partial thromboplastin time, prothrombin time and thrombin time, showed no major intraoperative changes in either group. Fibrinogen levels decreased in both groups, but no significant difference was found between the two groups. The only significant difference between group $\mathrm{A}$ and $\mathrm{B}$ was a more sustained increase in fibrinolytic activity after graft recirculation in group A. Postoperatively, restoration of fibrinogen, antithrombin-III and $\alpha_{2}$-antiplasmin levels was slightly faster in group $B$, resulting in significantly higher levels during the first day. We conclude that, in this animal model, APLT is associated with significantly lower blood loss and less severe fibrinolytic activity, than OLT. This difference might result from the lack of an anhepatic period and the reduced surgical trauma in auxiliary heterotopic liver transplantation.
\end{abstract}

Key words: Liver transplantation, auxiliary, in pigs - Hemostasis, in liver transplantation, in pigs - Auxiliary liver transplantation, hemostasis, in pigs

Although orthotopic liver transplantation (OLT) has become an accepted method to treat patients with endstage chronic liver disease, it is still associated with massive intraoperative blood loss and the use of large amounts of blood products $[9,17]$. Excessive blood loss is associated with an increased perioperative mortality and morbidity [32]. Massive transfusion of blood productsalsocontributes significantly to the total cost of liver transplantation [32].

Offprint requests to: R. J. Porte
Bleeding of surgical origin may be seriously complicated by specific hemostatic deteriorations, which occur especially during the anhepatic and post-anhepatic periods $[9,24]$. Disseminated intravascular coagulation (DIC), primary increased fibrinolysis, or a combination of both processes, have been suggested as a major cause of bleeding in orthotopic liver transplantation $[12,13,21,24]$. Lack of hepatic clearance of activated coagulation factors or activators of the fibrinolytic system may lead to severe disturbances of the hemostasis system in the anhepatic phase of OLT $[10,18]$.

Auxiliary heterotopic liver transplantation has been proposed as an alternative to hepatic replacement. The main theoretical advantage of auxiliary liver transplantation is avoidance of the technical hazards of recipient hepatectomy and the lack of an anhepatic period $[7,29]$. A second advantage may be that the recipient is not, at the outset, totally dependent on the function of the homograft. These differences might contribute to less severe hemostatic disorders and the usage of smaller amounts of blood products. However, information on this technique and its effect on hemostasis is limited.

Auxiliary heterotopic liver transplantation, though attractive, cannot be regarded as an alternative at present, and is probably limited to specific indications. Only a small number of auxiliary liver transplantations have been performed in humans $[7,30]$. The initial discouraging results have held up further application of this technique. Recently, many of the technical problems seem to have been resolved by improving the procedure and by using a partial graft $[26,27]$. The first clinical applications suggest that this improved technique of auxiliary partial liver transplantation (APLT) can be performed successfully without serious changes in blood coagulation and fibrinolysis, even in patients with poor preoperative hemostatic function $[15,23,31]$. However, objective information on the advantages and disadvantages of both techniques of liver transplantation can only be obtained from studies in which both techniques are evaluated under identical conditions. In addition, comparison of the two techniques can provide interesting information regarding the role of the 
Table 1. Body weight, intraoperative blood loss and infusion fluids in pigs that underwent orthotopic (OLT) and auxiliary partial (APLT) liver transplantation. Values are median (range). NS, Not significant

\begin{tabular}{llll}
\hline & $\begin{array}{l}\text { Group A (OLT) } \\
(n=9)\end{array}$ & $\begin{array}{l}\text { Group B (APLT) } \\
(n=9)\end{array}$ & $\begin{array}{l}\text { Signifi- } \\
\text { cance }\end{array}$ \\
\hline Body weight (kg) & $26.4(18.5-28.0)$ & $22.5(20.0-30.0)$ & NS \\
Blood loss (ml) & $825(250-1500)$ & $425(300-750)$ & $P<0.01$ \\
Ringers solution (ml) & $2250(1500-3300)$ & $1500(1500-3500)$ & NS \\
Haemaccel (ml) & $2250(1500-4000)$ & $1750(1500-2500)$ & NS \\
\hline
\end{tabular}

anhepatic phase and graft reperfusion in the origin of hemostatic disorders during OLT.

Therefore, we undertook a comparative study of OLT and APLT in healthy pigs. The effect of pre-existing differences in coagulation defects, as may be found in liver patients, was thus avoided, which made it possible to study the changes in hemostasis during specific stages of the surgical procedures. This study formed part of a larger comparative study on surgical and anesthetic management in OLT and APLT, part of which has been described elsewhere [3].

\section{Materials and methods}

Twenty-three female Yorkshire pigs were used in the experiments. The study was approved by the Committee for Laboratory Animal Research of the Erasmus University, Rotterdam. The animals were randomly allocated to two groups: animals in group $\mathrm{A}(n=12)$ underwent OLT and those in group $B(n=11)$ underwent APLT. The donor and recipient were matched according to a negative reaction in the mixed lymphocyte culture test (MLC) [19].

All operations were carried out under general anesthesia and the animals were ventilated using a Siemens 900 B Servo ventilator. During the operations, Ringers solution and Haemaccel were given for hemodynamic support as needed. Depending on the amount of blood loss, 1-2 IU whole blood ( $400 \mathrm{ml}$ each) was given in the period after graft recirculation.

Donor hepatectomy was performed using a conventional technique. After harvesting, the donor liver was perfused ex vivo by portal vein cannulation with 1 I Euro-Collins $\left(4^{\circ} \mathrm{C}\right)$ and grafted within $4 \mathrm{~h}$. Details of the surgical technique used are given below.

\section{Orthotopic liver transplantation}

In group A, OLT was performed by a standard procedure [28]. During the anhepatic period, blood flow from the operative area and the inferior part of the body was shunted away by a bypass from the portal and femoral vein to the jugular vein, using a heparin-coated extracorporeal circuit [5]. No systemic heparin was given.

\section{Heterotopic, auxiliary liver transplantation}

In group B, APLT was performed by using a partial liver graft. During bench surgery the left medial and lateral lobes of the liver were resected as described previously [26]. The partial graft, consisting of about $65 \%$ of the donor liver, was placed in the right subhepatic space, anastomosing the suprahepatic vena cava of the graft end-toside to the infrahepatic vena cava of the recipient. The donor portal vein was anastomosed end-to-side to the recipient portal vein and an end-to-side anastomosis was made between the graft hepatic artery to the recipient's infrarenal aorta. Bile flow was reconstituted by a choledochoduodenostomy. In this type of liver transplantation no shunt is necessary for the decompression of the splanchnic circulation during portal clamping. None of the animals received systemic heparin. No immunosuppressive drugs were given in either group.

\section{Blood loss and blood sampling}

Blood loss was quantified by measuring the amount of blood sucked away from the surgical field, and collected in Buleaux bottles during the operation.

Intraoperative blood samples $(20 \mathrm{ml})$ were taken from an arterial line, while in the postoperative period blood was collected from a central venous line or by puncturing the jugular vein. A part of the blood sample $(18 \mathrm{ml})$ was divided into two polystyrene test tubes, containing $1 \mathrm{ml}$ ice-cold trisodium citrate $0.11 \mathrm{~mol} / 1(9 \mathrm{vol}+1 \mathrm{vol})$ and immediately placed on melting ice. Plasma was collected after centrifugation ( $2800 \mathrm{~g}, 4^{\circ} \mathrm{C}, 30 \mathrm{~min}$ ), snap-frozen and stored in small aliquots at $-70^{\circ} \mathrm{C}$ until used. A smaller part of the blood sample $(2 \mathrm{ml}$ ) was collected into $0.045 \mathrm{ml} 15 \%$ solution of $6.75 \mathrm{mg}$ EDTA.

In both groups preoperative blood samples were taken immediately after induction of ancsthesia. The other blood samples were taken $5 \mathrm{~min}$ after anastomosis of the portal vein (recirculation of the graft), 5 min after anastomosis of the hepatic artery, $2 \mathrm{~h}$ and $3 \mathrm{~h}$ after transplantation and on postoperative days $1,2,7,10,14$ and 21 . In group A (OLT), one extra blood sample was taken 10 min before the end of the anhepatic phase.

\section{Hemostasis studies}

Congulation. The activated partial thromboplastin time (APTT), prothrombin time (PT) and thrombin time (ThT) were measured as described previously [22]. Thrombelastography (TEG) was performed in citrated plasma [20]. The $r$-value was defined as the time interval between the start of the registration and the first deflection on the TEG recording. The $k$-value was defined as the time interval after the first deflection until an amplitude of $10 \mathrm{~mm}$ was reached.
Table 2. Survival and causes of death after orthotopic (OLT) and auxiliary partial (APLT) liver transplantation

\begin{tabular}{lllll}
\hline Pig & \multicolumn{2}{l}{ Group A (OLT) } & \multicolumn{2}{l}{ Group B (APLT) } \\
\cline { 2 - 5 } & $\begin{array}{l}\text { Survival } \\
\text { (days) }\end{array}$ & Cause of death & $\begin{array}{l}\text { Survival } \\
\text { (days) }\end{array}$ & Cause of death \\
\hline 1 & 7 & Rejection & 35 & Sacrificed in good health \\
2 & 17 & Cholangitis & 8 & Volvulus of jejunum \\
3 & 2 & Not clear & 15 & Volvulus of jejunum \\
4 & 94 & Sacrificed in good health & 50 & Sacrificed in good health \\
5 & 72 & Sacrificed, leg abscess & 86 & Sacrificed in good health \\
6 & 33 & Not clear & 91 & Strangulated hernia \\
7 & 25 & Cholangitis & 159 & Sacrificed in good health \\
8 & 5 & Volvulus of jejunum & 93 & Sacrificed in good health \\
9 & 38 & Bile leakage & 23 & Purulent pneumonia \\
\hline
\end{tabular}




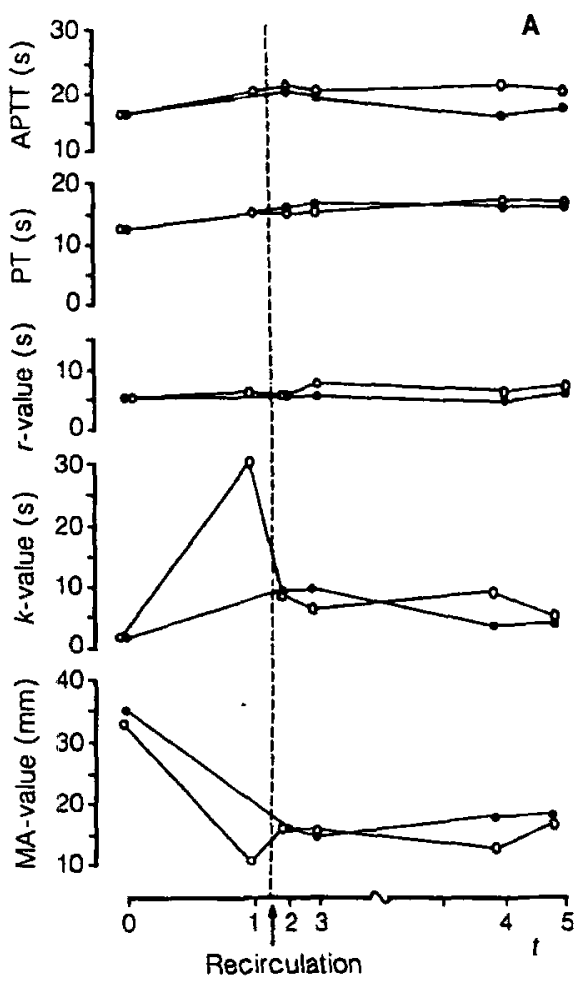

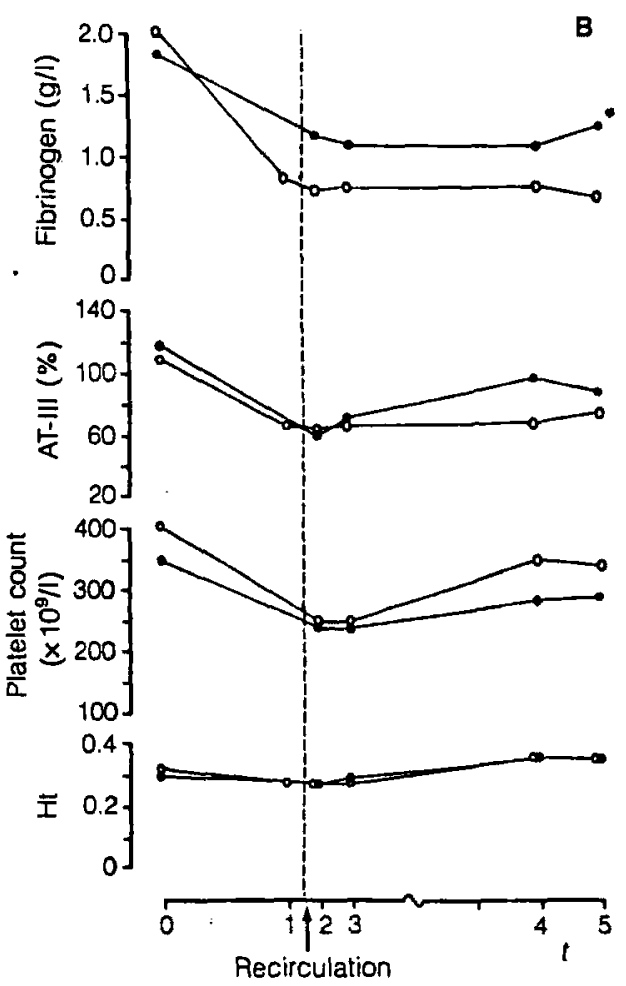

Fig.1. A $A P T T, P T$, $r$-value, $k$-value and maximum amplitude ( $M A$ ) of thrombelastogram in animals that underwent liver transplantation. O OLT (group A); APLT (group B) (median values). B Fibrinogen, AT-III, platelet count and hematocrit $(\mathrm{Ht})$. O OLT (group A); APLT (group B) (median values). $P<0.05$, comparison between group $A$ and B. 0 Preoperative; $l$ end anhepatic phase in OLT; $25 \mathrm{~min}$ after recirculation; $35 \mathrm{~min}$ after hepatic artery anastomosis; $42 \mathrm{~h}$ postoperative; $53 \mathrm{~h}$ postoperative. Median (range) time interval between 0 and 2 for OLT, 194 (144-250) min; for APLT, 120 (90-180) min; between 2 and 3 for OLT, $43(30-70) \mathrm{min}$; for APLT $40(25-105) \mathrm{min}$
The maximum amplitude (MA) represented the maximum deflection on the TEG recording. Fibrinogen was measured according to the method of Clauss [4] and antithrombin-III (AT-III) activity was assayed as described by Abildgaard et al. [1]. The vitamin $\mathbf{K}$ dependent factors II, VII and IX were determined by Normotest, according to the manufacturer's instructions (Nyegaard Diagnostica, Oslo, Norway). The hematocrit of each blood sample was measured to detect possible dilution effects.

Fibrinolysis. To determine the euglobulin clot lysis time (ECLT), standard euglobulin fractions of plasma were prepared at pH 5.9 with a plasma dilution of 1:10 [14]. Precipitates were redissolved in Tris/Tween buffer $(0.1 \mathrm{M} T R I S / \mathrm{HCl}$, containing $0.1 \% \mathrm{v} / \mathrm{v}$ Tween $80, \mathrm{pH} 7.5$ ), and to $0.2 \mathrm{ml}$ aliquots of the dissolved euglobulin fractions $0.1 \mathrm{ml}$ portions of calcium thrombin solution $\left(\mathrm{CaCl}_{2}\right.$ $25 \mathrm{mmol} / \mathrm{l}$ and thrombin $10 \mathrm{NIH} \mathrm{IU/l)}$ ) were added to induce clot formation. The lysis time of the clot was recorded. The disappearance of air bubbles was regarded as the endpoint of lysis. $\alpha_{2}$-Antiplasmin $\left(\alpha_{2}\right.$-AP) activity was measured according to the method of Friberger et al. [8]. Plasminogen was assayed in acidified plasma using urokinase (Choay, Paris, France) for activation of plasminogen and S-2251 (Kabi Vitrum Haematology, Amsterdam, The Netherlands) as substrate [19].

\section{Statistical analysis}

Statistical analysis was performed using the Wilcoxon signed rank test for paired data and the two-sample test for unpaired data. Values at $P<0.05$ were considered to be significant.

\section{Results}

In both groups nine animals survived longer than $24 \mathrm{~h}$ after transplantation and the data of these animals were used for analysis. The excluded animals died of second- ary complications which needed extensive therapeutic interventions, such as cardiac resuscitation, and which interfered with the standard surgical and anesthetic procedures essential for this study. In Table 1 body weight, blood loss and the amount of infusion fluids in group $\mathrm{A}$ (OLT) and group B (APLT) are compared. Median intraoperative blood loss in group A (OLT) was about twice as much as in group B (APLT) $(P<0.01)$ Survival and causes of death in both groups are shown in Table 2 . None of the animals died of postoperative hemorrhage. The main causes of early mortality were secondary to surgery and included intestinal strangulations. Autopsy demonstrated vital donor livers, with patency of all vascular anastomoses in all but one case in group A (no.1). The graft of this animal was firm and signs of intrahepatic cholestasis were present. In group B (APLT), vital grafts with patent vascular anastomoses were found in 5 of 7 animals for which autopsy data were available. In two animals (nos. 6 and 7) a pale, firm and atrophic auxiliary graft was found.

\section{Coagulation}

Intraoperatively, none of the investigated coagulation parameters was different between the two groups. A rather stable course of APTT and PT was found in both groups (Fig. 1 A), as also was found for ThT and NT. In fact, the only coagulation parameter that showed important changes during the operations was fibrinogen, for which a more than $40 \%$ decrease of the median levels was found during the operations in both groups (Fig.1B). This was also reflected by a prolongation of the $k$-value and a decrease of the MA on the TEG recordings (Fig. 1A). 


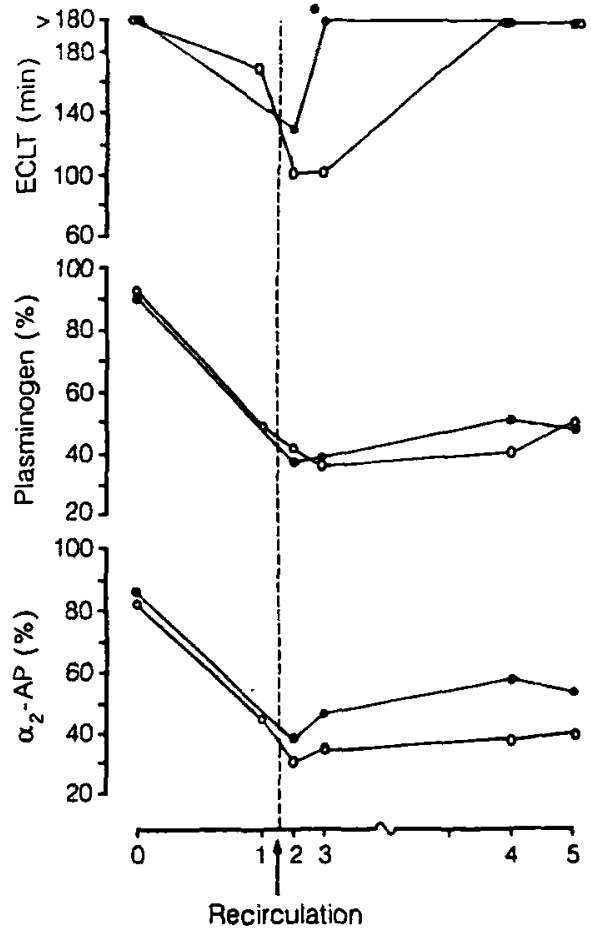

Fig. 2. ECLT, plasminogen and $\alpha_{2}$-antiplasmin ( $\alpha_{2}$-AP) in animals that underwent liver transplantation. O OLT (group A); - APLT (group B) (median values). $P<0.05$, comparison between group $A$ and $B$. $X$-axis notation as in Fig. 1

These changes could not be explained by hemodilution since no important changes in hematocrit were found (Fig.1 B). A slowly decreasing pattern was also seen for AT-III and platelet count (Fig. 1B).

\section{Fibrinolysis}

Important intraoperative changes were found in the investigated fibrinolytic parameters in both groups. Hyperfibrinolysis, as characterized by shortened ECLTs and reduction of $\alpha_{2}$-AP and plasminogen concentrations, was found $5 \mathrm{~min}$ after graft reperfusion in both OLT and APLT (Fig.2). During OLT an increased fibrinolytic activity, as measured by ECLT, was already present during the anhepatic period. In group A (OLT) a further increase of fibrinolytic activity was seen during the postreperfusion period, resulting in significantly shorter ECLTs at the time of completion of the arterial anastomosis, compared with group B (APLT) $(P<0.05)$. In both groups, ECLT became normal ( $>180 \mathrm{~s}$ ) $3 \mathrm{~h}$ after the operation. At this time plasma levels of plasminogen and $\alpha_{2}$-AP were still reduced. Restoration of $\alpha_{2}$-AP levels was apparently faster in group B (APLT), but the difference was not statistically significant.

\section{Long-term postoperative changes}

In both groups, a recovery of hemostatic parameters was observed during the first postoperative week. There were no differences in APTT, PT and NT. Fibrinogen, AT-III and $\alpha_{2}$-AP levels on the first day after surgery were higher in group B (APLT) $(P<0.01)$ (Fig. 3). Fibrinogen levels showed a peak on day 2 in group A (OLT) and on days 1 and 2 in group B (APLT) (Fig. 3). Platelet count reduced further during the first postoperative days, reaching a minimum on the second day in both groups. Thereafter a rapid recovery of platelet count was observed, rcsulting in a thrombocytosis (median values higher than $500 \times 10^{9} / \mathrm{l}$ ) at the end of the first week (Fig.3).

\section{Discussion}

The anhepatic phase in OLT is associated with serious changes in hemostasis, which may further complicate surgical bleeding and contribute to the need for massive blood transfusions $[12,24]$. Auxiliary liver transplantation potentially has benefits over OLT, as the technical hazards of the recipient hepatectomy and the subsequent anhepatic period are avoided. Therefore, auxiliary liver transplantation may, theoretically, be associated with less severe hemostatic deterioration, and it may be an attractive alternative to OLT. However, objective evidence on the potential advantages of auxiliary liver transplantation, with regard to blood loss and disturbances of hemostasis, are lacking. Although a comparison of OLT and auxiliary liver transplantation has been made in a previous study, this was primarily designed to study the effect of graft preservation damage on hemostasis, and insight into the specific changes due to the auxiliary transplantation procedure cannot be obtained from this study [11].

In the present study we investigated hemostasis after OLT and APLT using techniques which are currently used in humans. Both types of liver transplantation were performed in a controlled study in healthy pigs. The effects of pre-existing differences on coagulation defects, as may occur in liver patients, were thus avoided. This made it possible to study the specific changes in hemostasis due to the surgical procedures only. It should be noted that the results obtained in healthy pigs cannot be translated directly to the clinical situation. Liver patients undergoing transplantation usually already have severe hemostatic disorders before the operation, which has an important influence on the tendency for intraopertive bleeding [24]. Still, this study provided information on the hemostatic changes that occur intraoperatively and that are directly related to the transplantation procedure itself.

A lower blood loss was found in the animals that underwent APLT than in those that underwent OLT. This is in accordance with our experience in clinical APLT [31], and can, at least partly, be explained by the difference in surgical trauma, but this may very well be amplified by differences in the degree of intraoperative hemostatic deterioration. When comparing the hemostatic profile of the two groups, differences were not found in the blood coagulation system, but rather in the fibrinolytic system. In fact, the only minor changes in the routine clotting times, found in the OLT group, were comparable to the APLT group, without the anhepatic phase. This demonstrated that the changes are related to the surgical proce- 

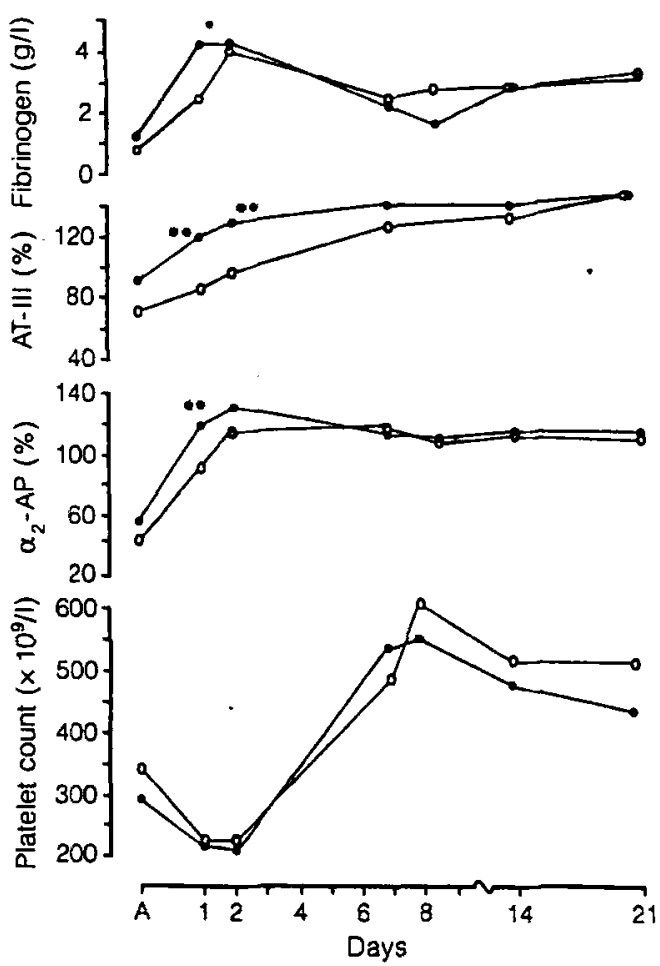

Fig. 3. Postoperative course of fibrinogen, AT-III, $\alpha_{2}$-AP and platelet count in animals that underwent liver transplantation. O OLT (group A); APLT (group B) (median values). $A 2 \mathrm{~h}$ after surgery. 'P<0.05," $P<0.01$, comparison between group A and B

dures in general, and not specifically due to the anhepatic phase in OLT.

The only coagulation parameter that showed serious alteration was fibrinogen. A decrease in fibrinogen levels and subsequent prolongation of $k$ value, representing clot formation rate, and a decrease in the MA value on TEG recordings, representing clot stiffness, were found in both OLT and APLT. Although the intraoperative decrease in fibrinogen levels was apparently more severe in OLT, this difference was not statistically significant. However, an ongoing postoperative decrease in fibrinogen levels after OLT did result in significantly lower levels compared with the APLT group $3 \mathrm{~h}$ after the operation. Several investigators have described a reduction of fibrinogen levels in experimental and clinical OLT $[10,12,13,16,18,21]$. Mechanisms of consumption, DIC trapping in the graft, fibrinogenolysis and the effect of hemodilution have been suggested to explain this phenomenon $[12,16,24]$. We did not find convincing evidence for DIC and/or hemodilution. AT-III levels never reached extremely low values and no serious changes in any of the clotting times or hematocrit were observed. The decrease in fibrinogen levels was most probably caused by a local consumption around the surgical wounds.

We also found signs of hyperfibrinolysis, as characterized by a shortened ECLT and decrease in plasminogen and $\alpha_{2}$-AP levels after graft recirculation in both groups. However, fibrinolytic activity was more severe and lasted longer in animals that underwent OLT. After recirculation of auxiliary grafts, the ECET showed a fast normalization, and ECLT was normalized in this group at the time of completion of the hepatic artery anastomosis. Many investigators have stressed the role of hyperfibrinolysis in the origin of bleeding complications in OLT. Recent studies in clinical OLT suggested that increased fibrinolytic activity is predominantly of primary origin $[12,16]$ and may result from a combination of reduced hepatic clearance and an increased release of tissue-type plasminogen activator $[6,25]$. The lack of an anhepatic phase and the remnant clearing function of the host liver might explain why we observed less severe fibrinolytic activation in APLT. In agreement with this, we recently demonstrated, in a clinical study, that signs of hyperfibrinolysis are only found in a minority of patients undergoing APLT [23]. Although the clinical relevance of hyperfibrinolysis in liver transplantation is still under discussion, this may be an important point of difference between OLT and APLT, and it may contribute to less frequent bleeding complications in APLT.

Another difference between OLT and APLT, found in this study, was an earlier restoration of some hemostasis parameters after the operation. Levels of fibrinogen, $\alpha_{2}-$ AP and AT-III were significantly higher in the APLT group on the first postoperative day. At first sight, this difference can be explained well by the reduced functional capacity of the orthotopically transplanted liver, and the possibility cannot be excluded that this effect is predominantly due to synthesis by the host liver in APLT. However, clinical observations in cirrhotic patients with severe preoperative coagulation defects who underwent APLT showed a similar fast restoration of $\alpha_{2}$-AP and AT-III levels $[23,31]$. Postoperatively, we observed a further decrease in platelet count in both groups. This is in agreement with clinical findings [21], but the mechanisms underlying this drop in platelet count are still not clear and will be the subject of further research.

The thrombocytosis observed in both groups after the first week can be ascribed to a reactively increased thrombopoiesis. Rebound thrombocytosis occurs because of a lag in the feedback mechanism associated with the platelet/megakaryocyte control mechanism [33]. In cirrhotic patients undergoing liver transplantation, a moderate to severe thrombocytopenia, due to splenomegaly, is usually present preoperatively. This may explain why such a thrombocytosis is less striking after successful clinical liver transplantations.

In conclusion, in comparing OLT and APLT in a controlled study, we observed a halving of intraopertive blood loss in animals that underwent APLT. No differences in the investigated coagulation parameters were found between the two groups. Although an increase in fibrinolytic activity was found during both types of liver transplantation, signs of hyperfibrinolysis were present during a longer period after graft recirculation in OLT. Postoperatively, an earlier normalization of disturbed hemostatic parameters was seen after APLT. It can be concluded that the anhepatic phase and reduced functional capacity of the donor liver during the early postreperfusion period play an important role in the hemostatic deterioration in OLT. Further clinical experience has to be awaited to determine the specific indications and advantages of APLT, compared to OLT. 
Acknowledgement. The assistance of the staff of the Laboratory for Experimental Surgery is gratefully acknowledged.

\section{References}

1. Abilgaard U, Lie M, Odegaard OR (1977) 'Antithrombin (heparin cofactor) assay with "new" chromogenic substrates (S2238 and Chromozym TH). Thromb Res 11:549-553

2. Bijnen AB, Dekkers-Bijma AM, Vriesendorp HM, Westbroek DL (1979) Value of the mixed lymphocyte reaction in dogs as a genetic assay. Immunogenetics 8: 287-297

3. Blankensteijn JD, Groenland THN, Baumgartner D, Vos LP, Kerkhofs LGM, Terpstra OT (1990) Interaoperative hemodynamics in liver transplantation comparing orthotopic with heterotopic transplantation in the pig. Transplantation 49:665-668

4. Clauss A (1957) Gerinnungsphysiologische Schnellmethode zur Bestimmung des Fibrinogens. Acta Haematol (Basel) 17: 237-246

5. Denmark SW, Shaw BW, Griffith BP, Starzl TE (1983) Venousvenous bypass without systemic anticoagulant in canine and human liver transplantation. Surg Forum 34: 380-382

6. Dzik WH, Arkin CF, Jenkins RL, Stump DC (1988) Fibrinolysis during liver transplantation in humans: role of tissue type plasminogen activator. Blood 71: 1090-1095

7. Fortner JG, Yeh SDJ, Shiu MH, Kinne DW (1979) The case for and technique of heterotopic liver grafting. Transplant Proc 11: 269-275

8. Friberger P, Knos M, Gustavsson S, Aurell L, Claeson G (1978) Methods for the determination of plasmin, antiplasmin and plasminogen by means of substrate S-2251. Haemostasis 7: 138-145

9. Goldsmith MF (1983) Liver transplantation: big business in blood. JAMA 250: 2904-2905

10. Groth CG. Pechet L, Starzl TE (1969) Coagulation during and after orthotopic transplantation of the human liver. Arch Surg 98: 31-34

11. Homatas J, Wasatapruek S. Kaulla E von, Kaulla KN von. Eisenman B (1969) Clotting abnormalitics following orthotopic and heterotopic transplantation of marginally preserved pig livers. Acta Hepato-Splenol 2: 14-27

12. Kang YG, Martin DJ, Marquez J. Lewis JH, Bontempo FA, Shaw BW. Starzl TE. Winter PM (1985) Intraopcrative changes in blood coagulation and thrombelastographic monitoring in liver transplantation. Anesth Analg 64: 888-896

13. Kaulla KN von. Kayne H, Kaulla E von. Marchioro TL, Starzl TE (1966) Changes in blood coagulation before and after hepatectomy or transplantation in dogs and man. Arch Surg 92: 71-79

14. Kluft C. Brakman P, Veldhuijzen-Stolk EC (1976) Screening of fibrinolytic activity in plasma euglobulin fractions on the fibrin plate. In: Davidson JF, Samama MM, Desnoyers PC (eds) Progress in chemical fibrinolysis and thrombolysis. Raven Press, New York, pp $57-65$

15. Knot EAR. Porte RJ, Terpstra OT, Schalm SW, Willemse PJA, Groenland THN, Stibbe J, Dooijwaard G. Nieuwenhuizen W (1988) Coagulation and fibrinolysis in the first human auxiliary partial liver transplantation in Rotterdam. Fibrinolysis 2: 111-117

16. Lewis JH. Bontempo FA, Kang YG, Spero JA. Ragni MV, Starzl TE (1986) Intraoperative coagulation changes in liver transplantation. In: Winter PM, Kang YG (eds) Hepatic transplantation. Praeger Publishers, New York, pp 142-150
17. Lewis JH, Bontempo FA, Cornell FW, Kiss JE. Larson P, Ragni MV, Rice EO, Spero JA, Starzl TE (1987) Blood use in liver transplantation. Transfusion 27:222-225

18. Moriau M, Kestens PJ, Otte JB, Masure R (1972) Hemostatic changes during hepatectomy, orthotopic liver transplantation, and graft rejection: an experimental and clinical study. In: Kaulla $\mathrm{KN}$ von (ed) Coagulation problems in transplanted organs. Thomas, Springfield, Ill, pp 16-23

19. Mussoni L, Raczka E, Chmielewska J, Donati MB, Latallo ZS (1979) Plasminogen assay in rabbit, rat and mouse plasma using the chromogenic substrate S-2251. Thromb Res 15: 341-349

20. Nicola P de (1957) Thrombelastography. Thomas, Springfjeld, Ill

21. Owen CA, Rettke SR, Bowie EJW, Cole TL, Jensen CC, Wiesner RH, Krom RAF (1987) Hemostatic evaluation of patients undergoing liver transplantation. Mayo Clin Proc 62: 761-772

22. Porte RJ, Jong E de, Knot EAR, Maat MPM de, Terpstra OT, Urk $H$ van, Groenland THN (1987) Monitoring heparin and hemostasis during reconstructions of the abdominal aorta. Eur $\mathrm{J}$ Vasc Surg 1: 397-402

23. Porte RJ, Knot EAR, Maat MPM de, Willemse PJA, Schalm SW, Stibbe J, Groenland THN, Terpstra OT (1988) Fibrinolysis detected by thrombelastography in heterotopic, auxiliary liver transplantation: effect of tissue type plasminogen activator. Fibrinolysis 2 [Suppl 3]: 67-73

24. Porte RJ, Bontempo FA, Knot EAR (1989) Hemostasis in liver transplantation: a review. Gastroenterology 97: 488-501

25. Porte RJ, Bontempo FA, Knot EAR, Lewis JH, Kang YG, Staral TE (1989) Systemic effect of tissue plasminogen activator associated fibrinolysis and the relation with thrombin generation in orthotopic liver transplantation. Transplantation 47: 978-984

26. Reuvers CB, Terpstra OT, Boks AL, Groot GH de, Jeekel J, Kate FWJ ten, Kooy PPM, Schalm SW (1985) Auxiliary transplantation of part of the liver improves survival and provides support in pigs with acute liver failure. Surgery 98: 914-921

27. Reuvers CB, Terpstra OT, Kate FWJ ten, Kooy PPM, Molenaar JC, Jeekel J (1985) Long-term survival of auxiliary partial liver grafts in DLA-identical littermate beagles. Transplantation 39: 113-118

28. Starzl TE, Iwatsuki S. Thiel DH van, Gartner JC, Zitelli BJ, Malatack JJ, Schade RR, Shaw BW, Hakala TR, Rosenthal HJT, Porte KA (1982) Evolution of liver transplantation. Hepatology $2: 614-6.36$

29. Terpstra OT, Schalm SW, Reuvers CB, Baumgartner D, Groenland THN, Kate FWJ ten. Stibbe J, Terpstra JL, Weimar W, Willemse PJA (1987) The role of auxiliary liver transplantation. Transplant Proc 19: 4370-4372

30. Terpstra OT, Reuvers CB. Schalm SW (1988) Auxiliary heterotopic liver transplantation. Transplantation 45: 1003-1007

31. Terpstra OT, Schalm SW, Weimar W, Willemse PJA, Baumgartner D. Groenland THN, Kate FWJ ten, Porte RJ, Rave S de, Reuvers CB. Stibbe J, Terpstra JL (1988) Auxiliary partial liver transplantation for end-stage chronic liver disease. N Engl J Med 319: 1507-1511

32. Thiel DH van. Tarter R, Gavaler JS, Potanko WM, Schade RR (1986) Liver transplantation in adults. An analysis of costs and benefits at the University of Pittsburgh. Gastroenterology 90: 211-216

33. Trowbridge EA, Martin JF (1984) An analysis of the platelet and polyploid megakaryocyte response to acute thrombocytopenia and its biological implications. Clin Phys Physiol Meas 5: 263-277 